\title{
Carcinoma of the breast in a male with hypogonadotropic hypogonadism
}

\author{
R. L. PRINCE \\ M.B., Ch.B., B.Sc., F.R.A.C.P. \\ Department of Medicine, University of Western Australia, Nedlands, Western Australia
}

\begin{abstract}
Summary
There is an increased risk of development of carcinoma of the breast in males with hypogonadism due to Klinefelter's syndrome. A patient with isolated hypogonadotropic hypogonadism and gynaecomastia developed an intraduct carcinoma of the breast. This is believed to be the first reported case of this association.
\end{abstract}

KEY WORDS: gynaecomastia, anosmia.

\section{Introduction}

Although a twentyfold increase in the incidence of carcinoma of the breast has been documented in hypogonadism due to Klinefelter's syndrome (Scheike, Visfeldt and Petersen, 1973) it has not previously been described in association with other causes of hypogonadism.

\section{Case report}

The patient, aged 50 years, presented with a history of many years of fatigue and mental vagueness which was worse in the evenings. The symptoms were thought to be worse since carcinoma of the breast had been diagnosed 2 years previously and the patient had been considered to be depressed.

Puberty occurred about the age of 15 years and was associated with marked persistent gynaecomastia. Although libido was always low, the patient married when 33 years old but had no children. For the 2 years before presentation he had been totally impotent. At the age of 48 years, following the development of a blood-stained discharge from the left nipple, a tumour was excised from the left breast. The histology was reported as showing a scirrhous invasive ductal carcinoma with multifocal intraduct papillary carcinoma. Four months later he had a prophylactic mastectomy of the right breast. Histology of this breast showed only simple hyperplasia of a few mammary ducts. There was no family history of hypogonadism or infertility. The patient was the third of four brothers the other three of whom have had children of their own.

On examination he was of eunuchoidal propot: tions. Height was $185 \mathrm{~cm}$, span $195 \mathrm{~cm}$ and the lower segment $97 \mathrm{~cm}$. His beard was sparse and he lacked $\Phi$ male escutcheon. His penis was $6 \mathrm{~cm}$, his left testis $1 \%$ $\mathrm{ml}$, and the right testis was $15 \mathrm{ml}$. Testing of olfactorid function showed a lack of ability to identify aromatio compounds. The remainder of the examination was normal with no evidence of mestastatic malignancy or other endocrine disorder. In particular there was no evidence of colour blindness, midline craniaf defect, cerebellar ataxia, nerve deafness or meptal retardation.

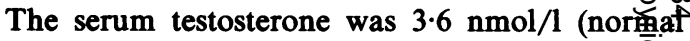
10-35) with a luteinizing hormone (LH) level of 3 Q (normal 4-15) and a follicle stimulating hormone (FSH) level of $2 \mathrm{u} / 1$ (normal 2-18). Thyroid functio tests showed an effective thyroxine ratio of $0.9 \%$ (normal 0.90 to $1 \cdot 10$ ) with a thyroid stimulating hormone (TSH) level of $2.3 \mathrm{mu} / 1$ (normal <6). The serum prolactin was $5 \mu \mathrm{g} / 1$ (normal $<25)$. The results of dynamic pituitary testing and in particular the LE and FSH responses to luteinizing hormone releasing hormone (LHRH) were within the normal range of response. Skull radiology and computerized axiap tomography were normal. Leucocyte karyotyping showed a normal 46 XY pattern.

\section{Discussion}

This patient had evidence of hypogonadotropie hypogonadism due to an isolated hypothalamie defect. The eunuchoidal stature together with thg history of gynaecomastia suggest a defect dating from puberty. The low serum testosterone with low norma LH and FSH both of which responded to LHRIA infusion suggest a hypothalamic defect (Roth et at 1972) which was isolated in that there was $n \notin$ evidence of other hormonal deficit either clinically of on dynamic testing. The patient also had hyposmia which has been described in association with hypo 0 gonadotropic hypogonadism (Kallmann's syndrome 
although there were no other stigmata of this syndrome. A partial defect in gonadotropin production resulting in relatively normal testicular size has also been described (Pasqualini and Bur, 1955). The occurrence of gynaecomastia is variable but has been documented in males with hypogonadotropic hypogonadism (Males, Townsend and Schneider, 1973); however the development of carcinoma of the breast has not previously been reported.

In view of the increased incidence of carcinoma of the breast in Klinefelter's syndrome it is reasonable to suggest that hypogonadism predisposes to the development of carcinoma of the breast. This may be due either to the increased amount of breast tissue itself, although this is controversial (Scheike and Visfeldt, 1973), or the hormonal and metabolic state associated with hypogonadism. The development of carcinoma of the breast in this patient suggests that the increased incidence in Klinefelter's syndrome is due to hypogonadism and not due to other aspects of the chromosomal defect. The histological classification of breast tumours in Klinefelter's syndrome reviewed by Schieke et al. (1973) was either intraduct, as in this case, or scirrhous adenocarcinoma.

In conclusion, in male patients with carcinoma of the breast hypogonadism should be considered, which may be due to a primary gonadal defect as in Klinefelter's syndrome or due to a hypothalamic defect as in the patient described. Leucocyte karyotyping should be carried out as hypogonadotropic hypogonadism has been reported in Klinefelter's syndrome (Carter, Wiseman and Lee, 1977).

\section{References}

CarTer, J.N., Wiseman, D.G.H. \& LeE, H.B. (1977) Klinefelter's syndrome with hypogonadotropic hypogonadism. British Medical Journal, 1, 212.

Males, J.L., TownSEnd, J.L. \& Schneider, R.A. (1973) Hypogonadotropic hypogonadism with anosmia-Kallmann's syndrome Archives of Internal Medicine, 131, 501.

Pasqualini, R.Q. \& BUR, G. (1955) Hypoandrogenic syndrome with spermatogenesis. Fertility and Sterility, 6, 144.

Roth, J.C., KelCh, R.P., KaPlan, S.L. \& Grumbach, M.M. (1972) FSH and $\mathrm{LH}$ response to luteinizing hormone releasing factor in prepubertal and pubertal children, adult males and patients with hypogonadotropic and hypergonadotropic hypogonadism. Journal of Clinical Endocrinology and Metabolism, 35, 926.

SCHEIKE, O. \& VISFELDT, J. (1973) Male breast cancer. Gynaecomastia in patients with breast cancer. Acta Pathologica et Microbiologica Scandinavica, 81, 354.

Scheike, O., Visfeldt, J. \& Petersen, B. (1973) Male breast cancer. Breast cancer in association with the Klinefelter's syndrome. Acta Pathologica et Microbiologica Scandinavica, 81, 352.

(Accepted 21 July 1983) 